\title{
Non-canonical progesterone signaling in granulosa cell function
}

\author{
John J Peluso ${ }^{1,2}$ and James K Pru ${ }^{3,4}$ \\ Departments of ${ }^{1}$ Cell Biology and ${ }^{2}$ Obstetrics and Gynecology, University of Connecticut Health Center, \\ Farmington, Connecticut 06030, USA, ${ }^{3}$ The Center for Reproductive Biology and ${ }^{4}$ Department of Animal Science, \\ Washington State University, Pullman, Washington 99164, USA
}

Correspondence should be addressed to J J Peluso; Email: peluso@nso2.uchc.edu

\begin{abstract}
It has been known for over 3 decades that progesterone $\left(\mathbf{P}_{\mathbf{4}}\right)$ suppresses follicle growth. It has been assumed that $\mathbf{P}_{\mathbf{4}}$ acts directly on granulosa cells of developing follicles to slow their development, as $\mathbf{P}_{\mathbf{4}}$ inhibits both mitosis and apoptosis of cultured granulosa cells. However, granulosa cells of developing follicles of mice, rats, monkeys, and humans do not express the A or B isoform of the classic nuclear receptor for $P_{4}$ (PGR). By contrast, these granulosa cells express other $P_{4}$ binding proteins, one of which is referred to as $P G R$ membrane component 1 (PGRMC1). PGRMC1 specifically binds $\mathbf{P}_{4}$ with high affinity and mediates $\mathbf{P}_{\mathbf{4}}$ 's anti-mitotic and anti-apoptotic action as evidenced by the lack of these $P_{4}$-dependent effects in PGRMC1-depleted cells. In addition, mice in which PGRMC1 is conditionally depleted in granulosa cells show diminished follicle development. While the mechanism through which $\mathbf{P}_{\mathbf{4}}$ activation of PGRMC1 affects granulosa cell function is not well defined, it appears that PGRMC1 controls granulosa cell function in part by regulating gene expression in T-cell-specific transcription factor/lymphoid enhancer factor-dependent manner. Clinically, altered PGRMC1 expression has been correlated with premature ovarian failure/insufficiency, polycystic ovarian syndrome, and infertility. These collective studies provide strong evidence that PGRMC1 functions as a receptor for $\mathbf{P}_{\mathbf{4}}$ in granulosa cells and that altered expression results in compromised reproductive capacity. Ongoing studies seek to define the components of the signal transduction cascade through which $\mathbf{P}_{\mathbf{4}}$ activation of PGRMC1 results in the regulation of granulosa cell function.

Reproduction (2014) 147 R169-R178
\end{abstract}

\section{Introduction and historical perspective}

Progesterone $\left(\mathrm{P}_{4}\right)$ is synthesized and secreted from both the follicular and luteal components of the mammalian ovary (Monniaux et al. 1997). The corpora lutea secrete $P_{4}$ at the highest rate while $\mathrm{P}_{4}$ synthesis gradually increases as the follicles develop (Roy \& Greenwald 1987, 1996). Throughout the course of rat ovarian follicle development, the $\mathrm{P}_{4}$ concentration within follicular fluid gradually increases from $5 \mu \mathrm{M}$ on diestrus to $55 \mu \mathrm{M}$ on the evening of proestrus (Fujii et al. 1983). These elevated $\mathrm{P}_{4}$ levels play an essential role in regulating ovulation because ovulation is disrupted by treatment with $\mathrm{P}_{4}$ receptor (PGR) antagonists, such as RU486, or in mutant mice in which the PGR is eliminated (Curry \& Nothnick 1996, Lydon et al. 1996, Pall et al. 2000, Robker et al. 2000, Svensson et al. 2000, Conneely et al. 2002). Because these $\mathrm{P}_{4}$-dependent effects are mediated to a large extent by PGR, which is expressed during the periovulatory period and not during folliculogenesis, this aspect of $\mathrm{P}_{4}$ 's actions will not be emphasized in this review.

While $\mathrm{P}_{4}$ activation of PGR and its role in the periovulatory period is well accepted, $\mathrm{P}_{4}$ also influences granulosa cell function in developing follicles prior to ovulation. These actions are controversial because granulosa cells of developing follicles do not express PGR (Park \& Mayo 1991, Natraj \& Richards 1993, Shao et al. 2003). This conclusion is based on the failure to detect PGR expression in rodent granulosa cells by northern blot, western blot, RT-PCR, in situ hybridization and immunocytochemistry. Also, rat luteal cells do not express PGR (Park \& Mayo 1991). Thus, there is overwhelming evidence that rat and mouse granulosa and luteal cells do not express PGR. In addition, granulosa cells of monkeys do not express the PGR until the gonadotropin surge (Chandrasekher et al. 1991). Finally, immunohistochemical analysis fails to detect PGR in granulosa cells of human follicles, although PGR is readily detected in luteal cells (Suzuki et al. 1994).

In spite of the fact that granulosa cells of developing follicles do not express PGR, the rate at which follicles grow (i.e., rate of granulosa cell mitosis) is inversely associated with serum $\mathrm{P}_{4}$ levels (Butcher et al. 1974, Hirshfield 1984, Pedersen 1984). Further, $P_{4}$ inhibits follicular development in hypophysectomized hamsters 
(Moore \& Greenwald 1974), gonadotropin-primed hamsters (Kim \& Greenwald 1987), and rabbits (Setty \& Mills 1987), as well as cycling rats (Buffler \& Roser 1974). That intraovarian $\mathrm{P}_{4}$ regulates follicle development is clearly shown in monkeys, in which intraovarian insertion of a $\mathrm{P}_{4}$ implant into one ovary suppresses follicle development in that ovary without altering serum gonadotropin levels, which allowed follicles to continue to grow in the contralateral non- $\mathrm{P}_{4}$ implanted control ovary (diZerega \& Hodgen 1982). This is the best evidence that $P_{4}$ acts within the ovary to regulate follicle growth independent of its effects on serum gonadotropin levels.

Although these in vivo studies are consistent with a direct effect of $\mathrm{P}_{4}$ on developing follicles, they do not reveal the cellular site of $\mathrm{P}_{4}$ 's action. However, $\mathrm{P}_{4}$ affects the ability of granulosa cells of immature rats to secrete steroids in vitro (Schreiber et al. 1980, 1981, Fortune \& Vincent 1983), as well as to undergo mitosis and apoptosis in vitro (Luciano \& Peluso 1995, Peluso \& Pappalardo 1998). Finally, $\mathrm{P}_{4}$ inhibits mitosis (Peluso et al. 2002) and apoptosis (Peluso et al. 2001) of spontaneously immortalized granulosa cells (SIGCs), a cell line derived from rat granulosa cells (Stein et al. 1991) and, like freshly isolated primary rat granulosa cells, these cells do not express PGR (Peluso et al. 2002). These in vitro observations are difficult to reconcile with the findings that granulosa cells do not express PGR.

$\mathrm{P}_{4}$ influences not only the function of granulosa cells but also luteal cells, which are derived from granulosa cells. Specifically, inhibiting $\mathrm{P}_{4}$ synthesis results in structural changes similar to those associated with luteal regression (see review by Stouffer et al. (2013)). These changes are prevented by supplemental $\mathrm{P}_{4}$ treatment (Stouffer et al. 2013). However, the effect of RU486 treatment is variable, at times increasing while at other times decreasing $\mathrm{P}_{4}$ secretion. To explain these biological effects of $\mathrm{P}_{4}$ and RU486, Rothchild (1996) put forth the concept that $\mathrm{P}_{4}$ regulates the structure and steroidogenic capacity of luteal cells. His hypothesis, developed without the aid of molecular biological and genetic approaches, further states that $\mathrm{P}_{4}$ can act through at least two different pathways but RU486 only acts through one of these pathways. While PGR is expressed by primate luteal cells (Chandrasekher et al. 1991), PGR is not expressed in rodent luteal cells (Park \& Mayo 1991, Natraj \& Richards 1993, Cai \& Stocco 2005). These observations raise the possibility of other receptors within luteal cells that mediate some of the $\mathrm{P}_{4}$ 's actions.

\section{Identification of a novel $\mathbf{P}_{4}$ binding protein in granulosa and luteal cells}

How $\mathrm{P}_{4}$ might then affect granulosa and luteal cell function in the absence of PGR? Ligand binding studies carried out in the late 1970s (Schreiber \& Erickson 1979, Schreiber \& Hsueh 1979) and early 1980s (Naess 1981) reveal that immature rat ovaries, which are composed mainly of developing ovarian follicles that lack PGR, specifically bind $\mathrm{P}_{4}$. Rat luteal cells also bind $\mathrm{P}_{4}$ (Cai \& Stocco 2005). Therefore, these binding studies indicate that the granulosa cells of immature rat ovaries and rat luteal cells express a $\mathrm{P}_{4}$ binding protein that is not the PGR and may function as a mediator of $\mathrm{P}_{4}{ }^{\prime}$ s actions.

Interestingly, there are two different families of progestin binding proteins that could mediate $\mathrm{P}_{4}$ 's actions in these cells. The first family is progestin AdipoQ receptors (PAQRs), initially identified in fish oocytes by Dr Peter Thomas's group (Zhu et al. 2003a,b). Thomas' studies reveal that the $\alpha$ type of the membrane progestin receptor (PAQR7) is expressed in human testis and ovaries. Moreover, mRNA encoding PAQR7 is detected in human granulosa/luteal cells isolated from women undergoing IVF, a human granulosa cell line, hGL5 cells (Peluso et al. 2009), and rat luteal cells (Cai \& Stocco 2005). Thus, a functional role for PAQRs in regulating $P_{4}$ 's actions within the mammalian ovary is likely.

\section{Expression and localization of $\mathbf{P}_{\mathbf{4}}$ membrane receptor component 1}

In addition to PAQRs, a second purported mediator of $\mathrm{P}_{4}$ 's action is PGR membrane component 1 (PGRMC1). PGRMC1 is highly expressed in granulosa cells of developing follicles and luteal cells. Specifically, PGRMC1 is detected in virtually all granulosa cells of rat antral follicles (Peluso et al. 2006). While present at the plasma membrane of every granulosa cell, it is also detected in the nucleus of a limited number of granulosa cells of small antral follicles (Fig. 1A). Within $48 \mathrm{~h}$ of gonadotropin treatment, PGRMC1 localization changes to almost exclusively at or near select regions of the plasma membrane with few cells showing nuclear staining (Fig. 1B). After hCG induction of ovulation and luteinization, PGRMC1 expression increases with 100\% of the luteal cells expressing high levels of PGRMC1 localized diffusely throughout the cytoplasm and nucleus (Peluso et al. 2006).

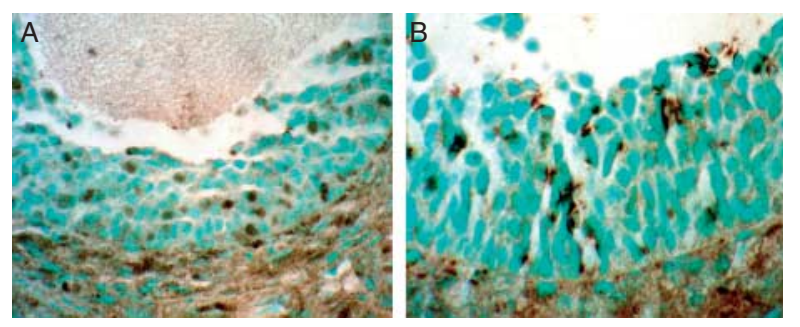

Figure 1 The expression of PGRMC1 in granulosa cells of antral (A) and preovulatory follicles (B) as assessed by immunohistochemistry. The antral follicle was obtained from an immature rat, while the preovulatory follicle was from an immature rat $48 \mathrm{~h}$ after PMSG injection. PGRMC1 was detected as a brown stain. The thecal layers at the base of each image show robust PGRMC1 expression. Data from Peluso et al. (2006). 
It is important to appreciate that in the cytoplasm, PGRMC1 is mainly thought to localize to the endoplasmic reticulum (Meyer et al. 1996, Falkenstein et al. 1999, Losel et al. 2005). As steroids can enter the cell, it is not necessary for PGRMC1 to be at the extracellular surface of the plasma membrane to transduce $\mathrm{P}_{4}$ 's action. However, BSA-conjugated $\mathrm{P}_{4}$ mimics $\mathrm{P}_{4}$ 's actions, suggesting that at least a fraction of $\mathrm{P}_{4}{ }^{\prime} \mathrm{s}$ receptor is localized to the extracellular surface of the plasma membrane (Peluso \& Pappalardo 1999). That some PGRMC1 localizes to the extracellular surface of the plasma membrane is conclusively demonstrated because PGRMC1 is detected among the plasma membrane proteins after biotinylation of these proteins (Peluso et al. 2006).

\section{PGRMC1 as a $\mathbf{P}_{\mathbf{4}}$ binding protein}

The expression studies imply that PGRMC1 could mediate $\mathrm{P}_{4}$ 's actions in granulosa cells of developing follicles. If so, then the first event in PGRMC1's mechanism is to bind $\mathrm{P}_{4}$. Interestingly, there are reports that PGRMC1 does not bind $\mathrm{P}_{4}$. These reports used bacterially expressed PGRMC1 fusion proteins (reviewed in Cahill (2007)) and not PGRMC1 fusion proteins expressed in mammalian cells. As a result, the bacterially expressed PGRMC1 may be unable to bind $\mathrm{P}_{4}$, as it may not be properly folded. By contrast, partially purified PGRMC1-fusion protein isolated from either SIGCs (Peluso et al. 2008) or human granulosa/luteal cells (hGL5 cells; Peluso et al. 2009) specifically binds $\mathrm{P}_{4}$ with high affinity $\left(\mathrm{EC}_{50} \approx 10 \mathrm{nM}\right.$ ) (Fig. $\left.2 \mathrm{~A}\right)$. In addition, the synthetic progestin, R5020, also binds PGRMC1 with the same affinity as $\mathrm{P}_{4}$ (Fig. 2A). Further, siRNA treatment specifically depletes Pgrmc1 mRNA and proteins levels and reduces the capacity of SIGCs to bind $\mathrm{P}_{4}$ (Peluso et al. 2008; Fig. 2B). Collectively, these studies demonstrate that PGRMC1 binds $\mathrm{P}_{4}$ and that it is required for $\mathrm{P}_{4}$ binding protein in SIGCs. However, as its name implies, PGRMC1 likely binds $\mathrm{P}_{4}$ as part of a complex with one member of the complex being membrane progestin receptor $\alpha$ (PAQR7) (Thomas et al. 2014), which is also expressed by SIGCs, rat ovarian cells (Cai \& Stocco 2005), and human granulosa/luteal cells (Peluso et al. 2009). These ligand-binding studies together with the expression data are supportive of PGRMC1 being a mediator of $\mathrm{P}_{4}$ 's action in both granulosa and luteal cells. However, this must be demonstrated by genetic manipulation of PGRMC1 levels.

\section{Biological actions mediated by $\mathbf{P}_{4}-$ PGRMC1 signaling in granulosa cells}

As previously indicated, $\mathrm{P}_{4}$ affects granulosa cell mitosis, apoptosis, and steroid synthesis in cells that do not express PGR. Given these actions, it is possible that
PGRMC1 is involved in each of these diverse aspects of granulosa cell biology. This concept was tested using both SIGCs and/or hGL5 cells as outlined in the following paragraphs.
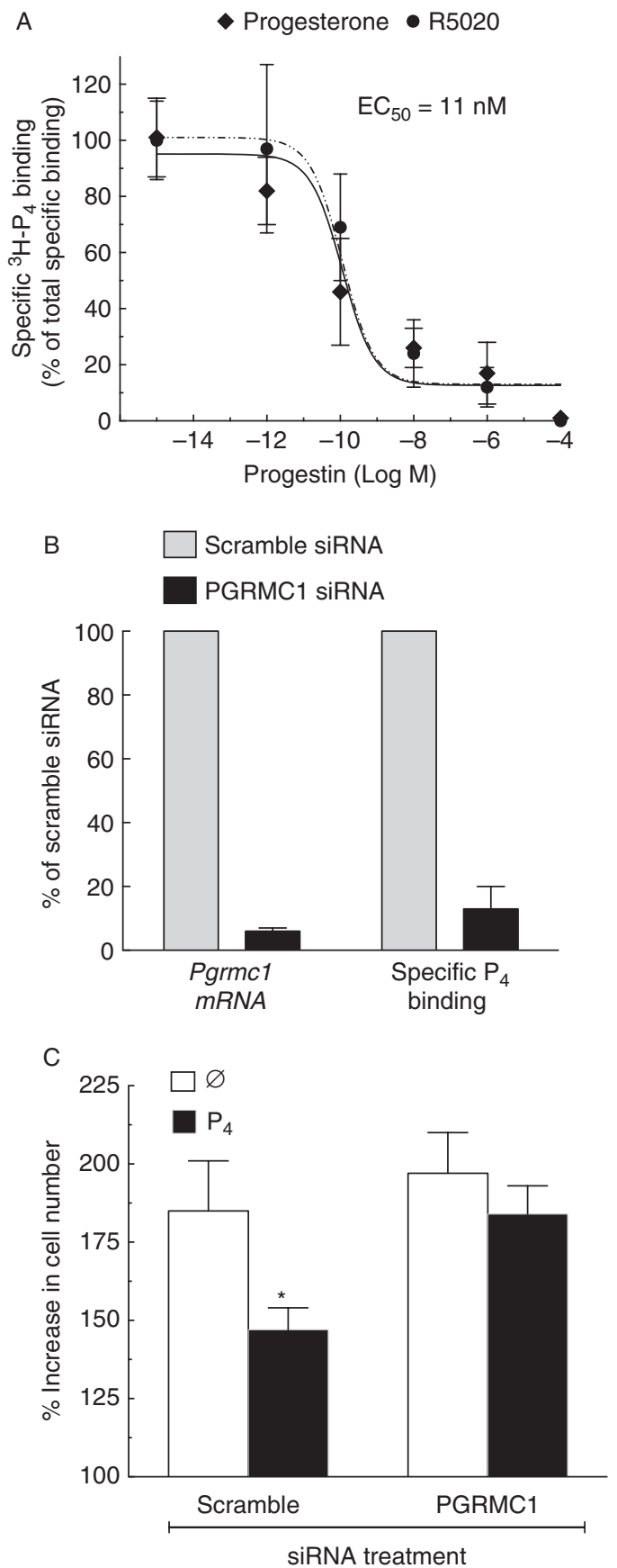

Figure 2 The capacity of partially purified PGRMC1-GFP to bind progesterone $\left(\mathrm{P}_{4}\right)$ and R5020 (A) and the effect of PGRMC1 siRNA treatment on Pgrmc1 mRNA levels and specific ${ }^{3} \mathrm{H}-\mathrm{P}_{4}$ binding to SIGCs (B). Data shown in (A) are adapted from Peluso et al. (2009) and the data shown in (B) are unpublished observations (J Peluso, unpublished observations) that confirm our published data (Peluso et al. 2008). The effect of $\mathrm{P}_{4}$ on serum-induced SIGC mitosis is shown in (C). Data shown in (C) are adapted from Peluso (2013). *indicates a value significantly different that control $(P<0.05)$. 


\section{$P_{4}$ and PGRMC1 as regulators of mitosis}

$\mathrm{P}_{4}$ attenuates mitogen-induced proliferation of rat granulosa cells isolated from both immature and preovulatory rat follicles (Peluso et al. 2006), human granulosa/luteal cells obtained from women undergoing ovulation induction for infertility treatment (Chaffkin et al. 1992), and SIGCs (Peluso et al. 2002). Further, $\mathrm{P}_{4}$ does so in a dose-dependent manner (10-1000 nM). Furthermore, treatment with PGRMC1 siRNA attenuates $\mathrm{P}_{4}{ }^{\prime}$ s ability to suppress the percentage of SIGCs incorporating BrdU and the percentage of cells in metaphase (J Peluso, unpublished observations). Finally, PGRMC1 siRNA treatment ablates $\mathrm{P}_{4}$ 's ability to suppress the number of cells present after $22 \mathrm{~h}$ of culture (Peluso 2013; Fig. 2C), while forced expression of PGRMC1 blocks entry into the cell cycle (J Peluso, unpublished observation). Taken together, these studies support the concept that $\mathrm{P}_{4}-\mathrm{PGRMC1}$ signaling is involved in regulating the rate of granulosa cell proliferation.

PGRMC1's ability to influence cell cycle progression is complex in that it appears to play specific roles at different stages of the cell cycle. For example, PGRMC1 regulates the transition from $G_{0}$ to $G_{1}$ stage of the cell cycle and also prolongs the duration of metaphase through its ability to interact with the mitotic spindle (Lodde \& Peluso 2011). These observations imply that PGRMC1 has different and specific modes of action that allow for its involvement in regulating the diverse signaling pathway that control different stages of the cell cycle.

\section{$P_{4}-P G R M C 1$ regulates apoptosis}

Over the same dose range that inhibits mitosis, $\mathrm{P}_{4}$ also suppresses the rate at which rat granulosa cells (Peluso et al. 2005), rat luteal cells (Peluso et al. 2005), human granulosa/luteal cells (Engmann et al. 2006), and SIGCs
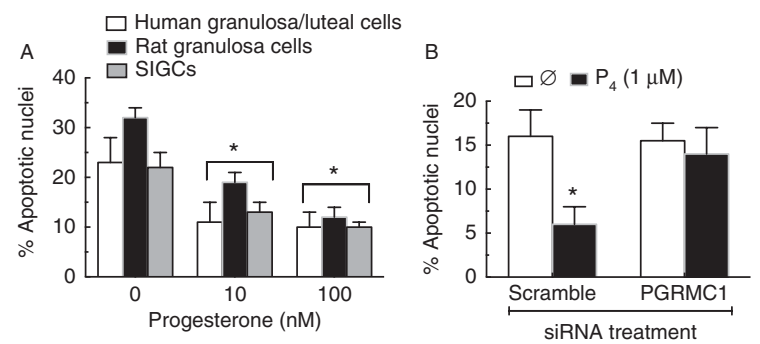

Figure 3 The inhibitory effect of progesterone $\left(\mathrm{P}_{4}\right)$ on apoptosis of human granulosa/luteal cells, rat granulosa cells, and rat luteal cells from PMSG-hCG primed immature rats 4 days after hCG treatment (A). Note that to detect the effects of $\mathrm{P}_{4}$ in luteal cells, endogenous $\mathrm{P}_{4}$ secretion was blocked with aminoglutethamide. The effect of $\mathrm{P}_{4}$ on the rate of spontaneously immortalized granulosa cells (SIGCs) apoptosis is shown in (B). The anti-apoptotic action of $\mathrm{P}_{4}$ is ablated after PGRMC1 siRNA treatment. ${ }^{*} A$ value that is significantly different from control $(P<0.05)$. In $(A)$, all values under the bracket marked with an * are different from their respective control values. Data shown in $(\mathrm{A})$ are redrawn from the following publications: (Engmann et al. 2006, Peluso et al. 2005, 2009). Data for (B) is from Peluso et al. (2008).
(Peluso et al. 2004) undergo apoptosis (Fig. 3A). It is important to appreciate that $\mathrm{P}_{4}$ 's anti-apoptotic effects can only be detected in mature rat luteal cells if endogenous $\mathrm{P}_{4}$ synthesis is inhibited with aminoglutethamide cells (Peluso et al. 2005), because the effect of supplemental $\mathrm{P}_{4}$ treatment is not observed in the presence of the large amount of $\mathrm{P}_{4}$ that is secreted by luteal cells (Peluso et al. 2006). As with mitosis, siRNA knockdown of PGMRC1 prevents $\mathrm{P}_{4}$ from inhibiting SIGCs from undergoing apoptosis (Peluso et al. 2008; Fig. 3B). In addition, forced expression of PGRMC1 increases the ability of $\mathrm{P}_{4}$ to suppress apoptosis (Peluso et al. 2008). These studies implicate $P_{4}-P G R M C 1$ signaling as a regulator of apoptosis.

\section{PGRMC1 and steroidogenesis}

$\mathrm{P}_{4}$ can also enhance its own synthesis (Rothchild 1996), and there is evidence to suggest that this action is mediated by PGRMC1. Specifically, this concept is based on the observation that PGRMC1 interacts with proteins sterol regulatory element binding protein cleavage-activating protein (SCAP) and insulin-induced gene 1 (INSIG1) that regulate cholesterol metabolism (Suchanek et al. 2005). Briefly, SCAP and INSIG1 control cholesterol metabolism by regulating the transcriptional action of sterol regulatory element binding protein, which induces the expression of StAR (Yang et al. 2002). $\mathrm{P}_{4}$ induces the expression of StAR in MA-10 testicular interstitial cells (Schwarzenbach et al. 2003) and promotes cholesterol and $\mathrm{P}_{4}$ synthesis in rat and human granulosa/luteal cells (Rung et al. 2005). Thus, the possibility exists that $\mathrm{P}_{4}$-PGRMC1 interaction regulates a complex series of protein-protein interactions that promote cholesterol and $\mathrm{P}_{4}$ biosynthesis. This concept is consistent with the observations that an antibody to PGRMC1 attenuates and forced PGRMC1 expression enhances adrenal steroidogenesis (Min et al. 2004).

The synthetic progestin, R5020, stimulates $P_{4}$ secretion from cultured rat granulosa cells (Fanjul et al. 1983, Ruiz de Galarreta et al. 1985), luteal cells (Rothchild 1996), MA-10 cells (Schwarzenbach et al. 2003) and hGL5 cells (Peluso et al. 2009). R5020's ability to stimulate $\mathrm{P}_{4}$ secretion is observed at concentrations equal to or $>16 \mu \mathrm{M}$. While $16 \mu \mathrm{M}$ may appear to be a pharmacological dose, it is within the physiological range, as women undergoing either natural or gonadotropin-stimulated cycles have $\mathrm{P}_{4}$ follicular fluid levels between 15 and $60 \mu \mathrm{M}$ (Tarlatzis et al. 1993, Kamel et al. 1994, Enien et al. 1995). However, human PGRMC1 binds R5020 with high affinity ( $E_{50}$ of $\approx 10 \mathrm{nM}$ ) (Peluso et al. 2009; Fig. 2A). Given this binding characteristic, all the R5020 binding sites within human PGRMC1 would be occupied by R5020 in the nanomolar range. Therefore, it is unlikely that the ability of R5020 to acutely promote $\mathrm{P}_{4}$ secretion is mediated 
through its ability to interact with PGRMC1. Further, PGRMC1-deplete hGL5 cells respond to R5020 by increasing their rate of $\mathrm{P}_{4}$ secretion (Peluso et al. 2009). Thus, these pharmacological and genetic-based observations make it clear that in hGL5 cells, PGRMC1 does not mediate $\mathrm{P}_{4}$ 's ability to acutely stimulate its own secretion. The mechanism through which R5020 promotes steroidogenesis in hGL5 cells is not known but could involve one of the other progestin binding proteins that are expressed by both human granulosa cells and hGL5 cells (i.e., PGR and PAQR family members) (Peluso et al. 2009).

\section{PGRMC1 and follicle growth in vivo}

PGRMC1's role in regulating granulosa cell mitosis and apoptosis is supported by examining follicle development in a conditional knockout mouse in which PGRMC1 is conditionally deleted from granulosa cells using anti-Müllerian hormone type II receptor cre recombinase transgenic mouse (Amhr2-cre). This analysis shows that ovaries from immature (22-25 days old) Pgrmc1 conditional knockout (cKO; $\mathrm{Amhr} 2^{\mathrm{cre} /+}$; Pgrmc $1^{f l / f l}$ ) mice have fewer antral follicles compared to either the control (i.e., $A m h r 2^{+/+} ; P g r m c 1^{f l / f l}$ ) or heterozygous $\left(A m h r 2^{\text {cre/ }+} ;\right.$ Pgrmc $1^{f l /+}$ ) female mice (Fig. 4). Although the ovaries of heterozygous mice have the same number of antral follicles as control mice, they have a higher percentage of atretic antral follicles (Fig. 4). The reason for this is unclear but a reduced level of PGRMC1 likely results in an increase in granulosa cell apoptosis, which would account for the increase in atretic follicles in the heterozygous mice.

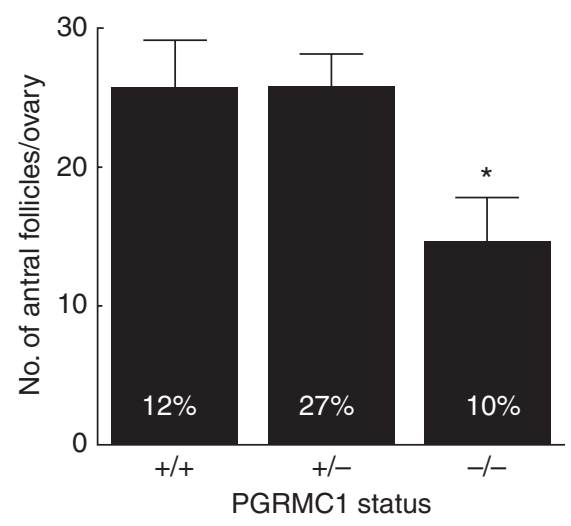

Figure 4 The total number of antral follicles within the ovaries of controls $(+/+)$, PGRMC1 heterozygous $(+/-)$, and PGRMC1 conditional knockout $(-/-)$ mice. Values are shown as means and S.E.M. with $\mathrm{n}$ of $6-8 /$ treatment group. ${ }^{*} \mathrm{~A}$ value is different from control $(P<0.05)$ as demonstrated by an ANOVA followed by Dunnett's multiple comparison test. The percentage of atretic antral follicles is shown in the base of each column. The percentage of atretic antral follicles is greater in the ovaries of $P g r m c 1^{+/-}$mice compared with the percentage in either the controls or $P g r m c 1^{-1-}$ mice as assessed by Fisher's exact $/ \chi^{2}$ tests $(P<0.05)$ (Peluso 2013).
Importantly, the heterozygous mouse mimics women with premature ovarian failure, who have $\approx 50 \%$ reduction in the level of PGRMC1 (Mansouri et al. 2008). Taken together, these findings are consistent with PGRMC1's role in maintaining the viability of granulosa cells and thus the process of folliculogenesis.

\section{$\mathbf{P}_{4}$-PGRMC1 signal transduction cascade}

That PGRMC1 mediates $\mathrm{P}_{4}$ 's ability to regulate mitosis and apoptosis is clearly illustrated through the use of siRNA-based knockdown and forced expression experiments. Unfortunately, the mechanism through which $\mathrm{P}_{4}$ activation of PGRMC1 regulates both mitosis and apoptosis of granulosa still remains to be determined. Specifically, how does $\mathrm{P}_{4}$ binding to PGRMC1 either at the plasma membrane or within the cytoplasm activate a signal transduction cascade that affects the rate at which granulosa cells undergo mitosis and/or apoptosis? There are a few studies indicating that $\mathrm{P}_{4}$ increases protein kinase G (PKG) activity (Peluso \& Pappalardo 2004, Peluso et al. 2007) and suppresses MEK/ERK activity (Peluso et al. 2003). As activators of PKG inhibit and MEK/ERK activity induces apoptosis (Peluso et al. 2003), the ability of $\mathrm{P}_{4}$ to regulate these two kinase pathways is probably a component of the anti-apoptotic $\mathrm{P}_{4}$-PGRMC1 signaling pathway. Unfortunately, siRNA-based studies have not been conducted, and therefore, it remains to be determined whether or not $\mathrm{P}_{4}$ activation of PGRMC1 is directly linked to $\mathrm{P}_{4}$ 's effects on these kinase cascades.

\section{Expression of genes in ovarian cells regulated by PGRMC1}

What is clear is that $\mathrm{P}_{4}$ activation of PGRMC1 alters gene expression, specifically genes that are involved in regulating mitosis and/or apoptosis. For example, $\mathrm{P}_{4}$ promotes SIGC survival by suppressing $\mathrm{Bad}$ and increasing Bcl2a1d expression, thereby changing the $\mathrm{Bcl} 21 \mathrm{~d}$ :Bad ratio to favor cell survival (Peluso et al. 2010). In human granulosa cells (hGL5 cells), PGRMC1 suppresses mRNA levels that encode activators of apoptosis such as caspase-3 (Peluso et al. 2012a). These PGRMC1-dependent actions would make the cells less likely to undergo apoptosis and promote mitosis (Peluso et al. 2012a).

\section{$P_{4}-P G R M C 1$ as a regulator of T-cell-specific transcription factor/lymphoid enhancer factor activity}

While PGRMC1 knockdown studies are important in that they reveal a role for $\mathrm{P}_{4}-\mathrm{PGRMC1}$ signaling in the regulation of gene expression, these types of studies provide little information about the mechanism through which $\mathrm{P}_{4}$-activated PGRMC1 alters gene expression. 


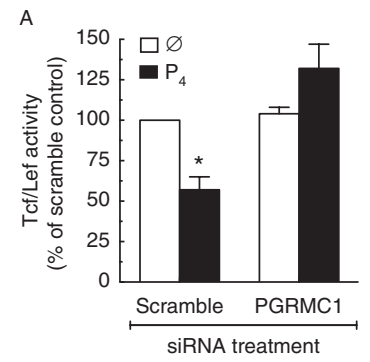

B

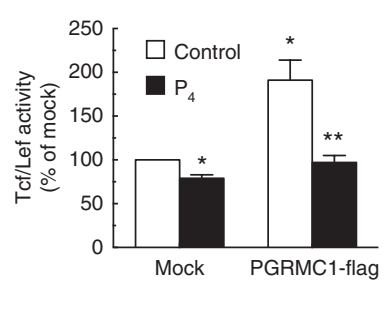

Figure 5 The effect of $\mathrm{P}_{4}$ and PGRMC1 on Tcf/Lef promoter in SIGCs as assessed by a luciferase reporter assay (A). In (B), the ability of $\mathrm{P}_{4}$ to suppress Tcf/Lef activity in the presence or absence of PGRMC1-Flag protein was assessed by a luciferase reporter. In all graphs, * indicates a value that is significantly different than control $(P<0.05), * *$ indicates a value significantly less than cells transfected with an expression vector encoding PGRMC1-Flag (Peluso et al. 2012b).

As indicated, PGRMC1 localizes to the nuclei of many granulosa cells in developing ovarian follicles. Similarly, PGRMC1 is also present within the nuclei of SIGCs that are proliferating but not in the nuclei of mitotically arrested SIGCs (Peluso et al. 2012b). The mechanism that regulates the cellular localization is unknown but PGRMC1's nuclear localization suggests that nuclear PGRMC1 may be directly involved in regulating gene expression. Furthermore, the most likely mechanism through which PGRMC1 influences gene expression is by either increasing or decreasing the activity of transcription factors. Recent studies indicate that in SIGCs, $\mathrm{P}_{4}$ significantly and faithfully suppresses T-cellspecific transcription factor/lymphoid enhancer factor (Tcf/Lef) activity and $\mathrm{P}_{4}$ 's ability to suppress Tcf/Lef activity is dependent on the presence of PGRMC1 (Peluso et al. 2012b; Fig. 5A). These observations provide some insight into how $\mathrm{P}_{4}-\mathrm{PGRMC1}$ signaling suppresses mitosis because the promoter region of genes involved in the initiation of mitosis, such as c-myc, possess Tcf/Lef consensus binding elements (Dang \& Lewis 1997, Dang et al. 2006).

The PGRMC1 siRNA study illustrates that $\mathrm{P}_{4}$ 's ability to inhibit Tcf/Lef activity is dependent on PGRMC1, but it does not demonstrate that nuclear PGRMC1 interacts with the Tcf/Lef site. One way to demonstrate that nuclear PGRMC1 interacts with the Tcf/Lef site is to use electrophoretic mobility shift assay (EMSA). Nuclear extract from SIGCs not treated with $\mathrm{P}_{4}$ contains proteins that bind to the Tcf/Lef probe. Moreover, nuclear extract from $\mathrm{P}_{4}$-treated SIGCs reduces the amount of Tcf/Lef probe bound to nuclear protein by $\approx 50 \%$ (J Peluso, unpublished observation). Unfortunately, the PGRMC1 antibody is not suitable for use in a super-shift EMSA, thus, PGRMC1 could not be shown to be one of the proteins that binds Tcf/Lef response elements.

This obstacle can be overcome by transfecting cells with an expression construct that encodes a PGRMC1Flag fusion protein. Importantly, the presence of PGRMC1-Flag increases Tcf/Lef activity by nearly twofold compared with controls and the PGRMC1-Flaginduced increase in Tcf/Lef activity is suppressed by $\mathrm{P}_{4}$ (Fig. 5B). After transfection with PGRMC1-Flag construct, a super-shift EMSA using an anti-Flag antibody reveals that PGRMC1-Flag is among the proteins that bind to the Tcf/Lef response element and $\mathrm{P}_{4}$ reduces the amount of PGRMC1 that is bound to this transcription factor site. Taken together, these studies demonstrate that $\mathrm{P}_{4}$ inhibits Tcf/Lef activity in part by suppressing the ability of nuclear PGRMC1 to interact with this transcription factor response element (Peluso et al. 2012b).

\section{Expression and function of other PGRMC family members}

Although progress is being made to define PGRMC1's role and mechanism of action in ovarian function, there are other members of the PGRMC family, including PGRMC2 and neudesin (NENF). As can be seen in Fig. 6, granulosa cells also express these other two PGRMC family members. Among these PGRMC family members, the relative level of expression is considerably different with PGRMC1 having the lowest level of expression, although Pgrmc1 mRNA levels in granulosa cells are higher compared with their levels in whole ovary. The higher Pgrmc1 mRNA levels in granulosa cells are consistent with its known function in granulosa cells. Interestingly, PGRMC2 is expressed at a five- to tenfold greater levels than PGRMC1, while NENF is expressed at nearly 100 times that of PGRMC1. This pattern of PGRMC family expression is also observed in mRNA levels obtained from the entire immature mouse ovary, as well as SIGCs (J Pru \& J Peluso unpublished observation).

Given the structural similarity between PGRMCs (Kimura et al. 2013), it is likely that PGRMC2 influences granulosa cell function. There are several ways that PGRMC2 could influence granulosa cell function including it: i) functioning as an antagonist to

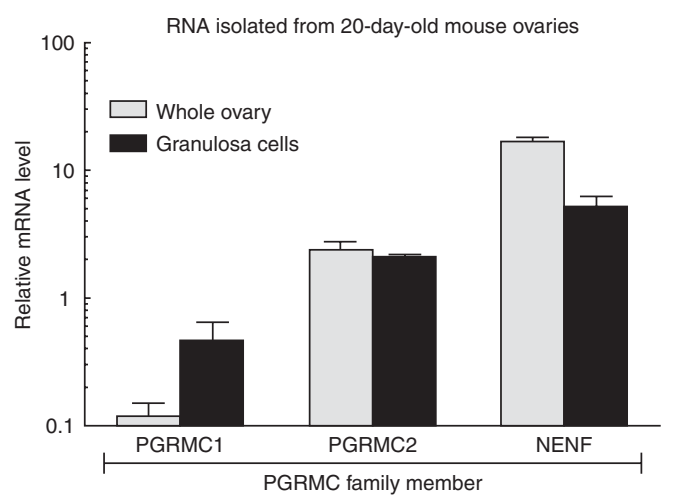

Figure 6 Expression of PGRMC family members in the immature mouse ovary and granulosa cells as assessed by real-time PCR. Note that the level of expression for the PGRMC family member is dramatically different with the lowest expression for PGRMC1, followed by PGRMC2 and then NENF, which has the highest level of expression (J Pru, unpublished observations). 
PGRMC1, ii) synergizing with PGRMC1, or iii) regulating a redundant pathway. Each of these possibilities merits experimental investigation. The likely key to understanding PGRMC2's function will be to determine the proteins to which it binds. It is probable that PGRMC2 will bind a unique set of intracellular proteins as well as some of the same proteins that bind PGRMC1. To date, the only published study on the function of PGRMC2 involves its role in promoting the migrations of ovarian cancer cells (Wendler \& Wehling 2013).

Like PGRMC2, NENF is highly expressed in granulosa cells and SIGCs and shares sequence homology to PGRMC1 (Kimura et al. 2013). As NENF is secreted by neural cells (Kimura et al. 2005, 2008), it is hypothesized that NENF binds $\mathrm{P}_{4}$, thereby reducing the amount of $\mathrm{P}_{4}$ available to interact with PGRMC1. However, there are reports indicating that the NENF does not bind $\mathrm{P}_{4}$, but in these studies, $\mathrm{P}_{4}$ binding was assessed using dot blots and bacterially expressed NENF (Kimura et al. 2005, 2008). Given that this approach is relatively insensitive and it is unclear if NENF bacterial protein is folded to allow for $\mathrm{P}_{4}$ binding, the capacity of NENF to bind $\mathrm{P}_{4}$ still remains to be determined.

There is another way for NENF to affect granulosa cell function. In SIGCs, $\mathrm{P}_{4}$ suppresses MAP kinase activity (Peluso et al. 2003), which likely accounts in part for both $\mathrm{P}_{4}$ 's anti-mitotic and anti-apoptotic actions (Peluso et al. 2003). Interestingly, NENF has neurotrophic actions and these actions are mediated through the activation of MAP kinase (Kimura et al. 2005, 2008). Thus, the balance between $\mathrm{P}_{4}$ and NENF could influence the overall activity of MAP kinase and thereby the fate of granulosa cells. However, a receptor for NENF has not been identified (Kimura et al. 2013) and this is required before any mechanism for NENF's action can be completely developed.

\section{Clinical correlations}

Although it has only been known that PGRMC1 is expressed in the mammalian granulosa cells since 2006 (Peluso et al. 2006), there are now three publications suggesting that it plays a clinically relevant role in regulating follicular function in women. The first report is from Dr Dahl's group in Sweden in which he identified a mother and daughter with an X; autosome translocation (Mansouri et al. 2008). This translocation results in a reduced expression of PGRMC1 by $50 \%$. The same publication describes a missense mutation in PGRMC1 that is observed in one of 67 women with premature ovarian failure/insufficiency. This mutation at amino acid 165 reduces the ability of PGRMC1 to transduce $\mathrm{P}_{4}$ 's anti-apoptotic action by $50 \%$ and also attenuates its ability to interact with several cytochrome P450 enzymes (Mansouri et al. 2008). In their second publication, Dahl's group reports that PGRMC1 levels are relatively constant throughout the menstrual cycle but are lower in postmenopausal women and women with premature ovarian failure and polycystic ovary syndrome (Schuster et al. 2010). Finally, an examination of the granulosa/luteal cells obtained from women undergoing ovulation induction as part of their infertility treatment reveal that women with elevated levels of Pgrmc1 mRNA levels have 30\% fewer follicles and few oocytes retrieved (Elassar et al. 2012). The reason for the association between higher levels of Pgrmc1 mRNA is not completely known but may be related to the finding that there is an increase in the methylation of the PGRMC1 promoter (Elassar et al. 2012).

Like PGRMC1, PGRMC2 appears to be associated with altered follicle development in women. This is based on the finding that young women with diminished ovarian reserve (i.e., fewer ovarian follicles) have elevated Pgrmc2 mRNA levels compared to normal young women (Skiadas et al. 2012). To date, there are no studies on ovarian function and NENF. Taken together, these correlative clinical studies provide new insight by demonstrating that genetic changes or altered expression of PGRMC family members affects follicle growth in women. These findings are consistent with actions of PGRMC family members observed in the studies on rodent granulosa cells both in vitro and in vivo.

\section{Summary and future research perspectives}

The biological actions of $\mathrm{P}_{4}$ on developing ovarian follicles have been known for several decades, but the receptors that mediate these effects remain a point of contention, as the granulosa cells of these follicles do not express PGR. The application of biochemical and genetic approaches reveal that PGRMC1 and possibly other PGRMC family members play important roles in this aspect of ovarian follicle function. Recent studies implicate PGRMC1 as a regulator of granulosa cell apoptosis and mitosis. Moreover, PGRMC1 functions to regulate gene transcription, in part through regulating Tcf/Lef transcription factor activity. Thus, the basic elements of the $\mathrm{P}_{4}-\mathrm{PGRMC1}$ signal transduction pathway have been identified in granulosa cells. Future research must now be directed toward determining the molecular steps that link $\mathrm{P}_{4}$-activated PGRMC1 to Tcf/Lef-dependent transcription and the subsequent regulation of mitosis, apoptosis, and steroidogenesis.

\section{Declaration of interest}

J K Pru has nothing to disclose. J J Peluso was awarded a patent on non-genomic regulators of progesterone's action.

\section{Funding}

These studies were supported by NIH grant R01 HD052740 awarded to J J Peluso and NIH grant R21 RR030264 awarded to J J Peluso and J K Pru and R21 HD066297 awarded to J K Pru. 


\section{Acknowledgements}

J J Peluso would like to thank the numerous fellows and students that have worked on non-canonical actions of progesterone, since this project was initiated by Dr Alberto Luciano of the University of Milian in 1994. The authors would also like to acknowledge the technical support provided by Anna Pappalardo, Xiufang Liu and Yuichi Niikura.

\section{References}

Buffler G \& Roser S 1974 New data concerning the role played by progesterone in the control of follicular growth in the rat. Acta Endocrinologica 75 569-578.

Butcher RL, Collins WE \& Fugo NW 1974 Plasma concentration of LH, $\mathrm{FSH}$, prolactin, progesterone and estradiol-17 $\beta$ throughout the 4-day estrous cycle of the rat. Endocrinology 94 1704-1708. (doi:10.1210/ endo-94-6-1704)

Cahill MA 2007 Progesterone receptor membrane component 1: an integrative review. Journal of Steroid Biochemistry and Molecular Biology 105 16-36. (doi:10.1016/j.jsbmb.2007.02.002)

Cai Z \& Stocco C 2005 Expression and regulation of progestin membrane receptors in the rat corpus luteum. Endocrinology 146 5522-5532. (doi:10.1210/en.2005-0759)

Chaffkin LM, Luciano AA \& Peluso JJ 1992 Progesterone as an autocrine/paracrine regulator of human granulosa cell proliferation. Journal of Clinical Endocrinology and Metabolism 75 1404-1408.

Chandrasekher YA, Brenner RM, Molskness TA, Yu Q \& Stouffer RL 1991 Titrating luteinizing hormone surge requirements for ovulatory changes in primate follicle. II. Progesterone receptor expression in luteinizing granulosa cells. Journal of Clinical Endocrinology and Metabolism 73 584-589. (doi:10.1210/jcem-73-3-584)

Conneely OM, Mulac-Jericevic B, DeMayo F, Lydon JP \& O'Malley BW 2002 Reproductive functions of progesterone receptors. Recent Progress in Hormone Research 57 339-355. (doi:10.1210/rp.57.1.339)

Curry TE Jr \& Nothnick WB 1996 Mifepristone and ovarian function. Clinical Obstetrics and Gynecology 39 486-497. (doi:10.1097/ 00003081-199606000-00022)

Dang CV \& Lewis BC 1997 Role of oncogenic transcription factor c-Myc in cell cycle regulation, apoptosis and metabolism. Journal of Biomedical Science 4 269-278. (doi:10.1007/BF02258350)

Dang CV, O'Donnell KA, Zeller KI, Nguyen T, Osthus RC \& Li F 2006 The c-Myc target gene network. Seminars in Cancer Biology 16 253-264. (doi:10.1016/j.semcancer.2006.07.014)

Elassar A, Liu X, Scranton V, Wu C \& Peluso J 2012 The relationship between follicle development and progesterone receptor membrane component-1 (PGRMC1) expression in women undergoing in vitro fertilization. Fertility and Sterility 97 572-578. (doi:10.1016/j.fertnstert. 2011.12.026)

Engmann L, Losel R, Wehling M \& Peluso JJ 2006 Progesterone regulation of human granulosa/luteal cell viability by an RU486-independent mechanism. Journal of Clinical Endocrinology and Metabolism 91 4962-4968. (doi:10.1210/jc.2006-1128)

Enien WM, el Sahwy S, Harris CP, Seif MW \& Elstein M 1995 Human chorionic gonadotrophin and steroid concentrations in follicular fluid: the relationship to oocyte maturity $\backslash$ and fertilization rates in stimulated and natural in-vitro fertilization cycles. Human Reproduction $\mathbf{1 0}$ 2840-2844.

Falkenstein E, Heck M, Gerdes D, Grube D, Christ M, Weigel M, Buddhikot M, Meizel S \& Wehling M 1999 Specific progesterone binding to a membrane protein and related nongenomic effects on $\mathrm{Ca}^{2+}$. fluxes in sperm. Endocrinology 140 5999-6002. (doi:10.1210/endo.140. 12.7304REF16=10.1095/biolreprod28.5.1078)

Fanjul LF, Ruiz de Galarreta CM \& Hsueh AJ 1983 Progestin augmentation of gonadotropin-stimulated progesterone production by cultured rat granulosa cells. Endocrinology 112 405-407. (doi:10.1210/endo-112-1405)
Fortune JE \& Vincent SE 1983 Progesterone inhibits the induction of aromatase activity in rat granulosa cells in vitro. Biology of Reproduction 28 1078-1089. (doi:10REF20=10.1095/biolreprod36.2.270)

Fujii T, Hoover DJ \& Channing CP 1983 Changes in inhibin activity, and progesterone, oestrogen and androstenedione concentrations, in rat follicular fluid throughout the oestrous cycle. Journal of Reproduction and Fertility 69 307-314.

Hirshfield AN 1984 Stathmokinetic analysis of granulosa cell proliferation in antral follicles of cyclic rats. Biology of Reproduction 31 52-58. (doi:10.1095/biolreprod31.1.52)

Kamel MA, Zabel G, Bernart W, Neulen J \& Breckwoldt M 1994 Comparison between prolactin, gonadotrophins and steroid hormones in serum and follicular fluid after stimulation with gonadotrophinreleasing hormone agonists and human menopausal gonadotrophin for an in-vitro fertilization programme. Human Reproduction 9 1803-1806.

Kim I \& Greenwald GS 1987 Stimulatory and inhibitory effects of progesterone on follicular development in the hypophysectomized follicle-stimulating hormone/luteinizing hormone-treated hamster. Biology of Reproduction 36 270-276. (doi:10.1095/biolreprod36.2.270)

Kimura I, Yoshioka M, Konishi M, Miyake A \& Itoh N 2005 Neudesin, a novel secreted protein with a unique primary structure and neurotrophic activity. Journal of Neuroscience Research 79 287-294. (doi:10.1002/ jnr.20356)

Kimura I, Nakayama Y, Yamauchi H, Konishi M, Miyake A, Mori M, Ohta M, Itoh N \& Fujimoto M 2008 Neurotrophic activity of neudesin, a novel extracellular heme-binding protein, is dependent on the binding of heme to its cytochrome b5-like heme/steroid-binding domain. Journal of Biological Chemistry 283 4323-4331. (doi:10.1074/jbc.M706679200)

Kimura I, Nakayama Y, Zhao Y, Konishi M \& Itoh N 2013 Neurotrophic effects of neudesin in the central nervous system. Frontiers in Neuroscience 7 111. (doi:10.3389/fnins.2013.0REF29=10.1111/ j.1432-1033.1996.0726u.x)

Lodde V \& Peluso JJ 2011 A novel role for progesterone and progesterone receptor membrane component 1 in regulating spindle microtubule stability during rat and human ovarian cell mitosis. Biology of Reproduction 84 715-722. (doi:10.1095/biolreprod.110.088385)

Losel R, Breiter S, Seyfert M, Wehling M \& Falkenstein E 2005 Classic and non-classic progesterone receptors are both expressed in human spermatozoa. Hormone and Metabolic Research 37 10-14. (doi:10. 1055/s-2005-861023)

Luciano AM \& Peluso JJ 1995 Effect of in vivo gonadotropin treatment on the ability of progesterone, estrogen, and cyclic adenosine $5^{\prime}$ monophosphate to inhibit insulin-dependent granulosa cell mitosis in vitro. Biology of Reproduction 53 664-669. (doi:10.1095/biolreprod53.3.664)

Lydon JP, DeMayo FJ, Conneely OM \& O'Malley BW 1996 Reproductive phenotypes of the progesterone receptor null mutant mouse. Journal of Steroid Biochemistry and Molecular Biology 56 67-77. (doi:10.1016/ 0960-0760(95)00254-5)

Mansouri MR, Schuster J, Badhai J, Stattin EL, Losel R, Wehling M, Carlsson B, Hovatta O, Karlstrom PO, Golovleva I et al. 2008 Alterations in the expression, structure and function of progesterone receptor membrane component-1 (PGRMC1) in premature ovarian failure. Human Molecular Genetics 17 3776-3783. (doi:10.1093/hmg/ddn274)

Meyer C, Schmid R, Scriba PC \& Wehling M 1996 Purification and partial sequencing of high-affinity progesterone-binding site(s) from porcine liver membranes. European Journal of Biochemistry/FEBS 239 726-731. (doi:10.1111/j.1432-1033.1996.0726REF36=10.1210/mend-5-7-967)

Min L, Takemori H, Nonaka Y, Katoh Y, Doi J, Horike N, Osamu H, Raza FS, Vinson GP \& Okamoto M 2004 Characterization of the adrenal-specific antigen IZA (inner zone antigen) and its role in the steroidogenesis. Molecular and Cellular Endocrinology 215 143-148.

Monniaux D, Huet C, Besnard N, Clement F, Bosc M, Pisselet C, Monget P \& Mariana JC 1997 Follicular growth and ovarian dynamics in mammals. Journal of Reproduction and Fertility. Supplement 51 3-23.

Moore PJ \& Greenwald GS 1974 Effect of hypophysectomy and gonadotropin treatment on follicular development and ovulation in the hamster. American Journal of Anatomy 139 37-48. (doi:10.1002/aja. 1001390103)

Naess O 1981 Characterization of cytoplasmic progesterone receptors in rat granulosa cells. Evidence for nuclear translocation. Acta Endocrinologica 98 288-294. 
Natraj U \& Richards JS 1993 Hormonal regulation, localization, and functional activity of the progesterone receptor in granulosa cells of rat preovulatory follicles. Endocrinology 133 761-769.

Pall M, Mikuni M, Mitsube K \& Brannstrom M 2000 Time-dependent ovulation inhibition of a selective progesterone-receptor antagonist (Org 31710 ) and effects on ovulatory mediators in the in vitro perfused rat ovary. Biology of Reproduction 63 1642-1647.

Park OK \& Mayo KE 1991 Transient expression of progesterone receptor messenger RNA in ovarian granulosa cells after the preovulatory luteinizing hormone surge. Molecular Endocrinology 5 967-978. (doi:10.1210/mend-5-7-967)

Pedersen T 1984 Follicular growth in the mouse ovary. In Oogenesis, pp 361-376. Eds J Biggers\& A Schuetz. Baltimore: University Park Press.

Peluso JJ 2013 Progesterone receptor membrane component 1 and its role in ovarian follicle growth. Frontiers in Neuroscience 7 99. (doi:10.3389/ fnins.2013.000REF46=10.1095/biolreprod.105.041061)

Peluso JJ \& Pappalardo A 1998 Progesterone mediates its anti-mitogenic and anti-apoptotic actions in rat granulosa cells through a progesterone-binding protein with gamma aminobutyric acidA receptor-like features. Biology of Reproduction 58 1131-1137. (doi:10.1095/biolreprod58.5.1131)

Peluso JJ \& Pappalardo A 1999 Progesterone maintains large rat granulosa cell viability indirectly by stimulating small granulosa cells to synthesize basic fibroblast growth factor. Biology of Reproduction 60 290-296.

Peluso JJ \& Pappalardo A 2004 Progesterone regulates granulosa cell viability through a protein kinase G-dependent mechanism that may involve 14-3-3sigma. Biology of Reproduction 71 1870-1878. (doi:10. 1095/biolreprod.104REF50=10.1210/jc.2009-0147)

Peluso JJ, Fernandez G, Pappalardo A \& White BA 2001 Characterization of a putative membrane receptor for progesterone in rat granulosa cells. Biology of Reproduction 65 94-101. (doi:10.1095/biolreprod65.1.94)

Peluso JJ, Fernandez G, Pappalardo A \& White BA 2002 Membraneinitiated events account for progesterone's ability to regulate intracellular free calcium levels and inhibit rat granulosa cell mitosis. Biology of Reproduction 67 379-385. (doi:10.1095/biolreprod67.2.379)

Peluso JJ, Bremner T, Fernandez G, Pappalardo A \& White BA 2003 Expression pattern and role of a 60-kilodalton progesterone binding protein in regulating granulosa cell apoptosis: involvement of the mitogen-activated protein kinase cascade. Biology of Reproduction 68 122-128. (doi:10.1095/biolreprod.102.007542)

Peluso JJ, Pappalardo A, Fernandez G \& Wu CA 2004 Involvement of an unnamed protein, RDA288, in the mechanism through which progesterone mediates its antiapoptotic action in spontaneously immortalized granulosa cells. Endocrinology 145 3014-3022. (doi:10.1210/en.2004-0067)

Peluso JJ, Pappalardo A, Losel R \& Wehling M 2005 Expression and function of PAIRBP1 within gonadotropin-primed immature rat ovaries: PAIRBP1 regulation of granulosa and luteal cell viability. Biology of Reproduction 73 261-270. (doi:10.1095/biolreprod.105.0REF58=10.1016/S0039-128 X(85)80006-4)

Peluso J, Pappalardo A, Losel R \& Wehling M 2006 Progesterone membrane receptor component 1 expression in the immature rat ovary and its role in mediating progesterone's antiapoptotic action. Endocrinology 147 3133-3140. (doi:10.1210/en.2006-0114)

Peluso JJ, Liu X \& Romak J 2007 Progesterone maintains basal intracellular adenosine triphosphate levels and viability of spontaneously immortalized granulosa cells by promoting an interaction between 14-3-3sigma and ATP synthase $\beta$ /precursor through a protein kinase G-dependent mechanism. Endocrinology 148 2037-2044. (doi:10.1210/en.2006-1603)

Peluso JJ, Romak J \& Liu X 2008 Progesterone receptor membrane component-1 (PGRMC1) is the mediator of progesterone's antiapoptotic action in spontaneously immortalized granulosa cells as revealed by PGRMC1 small interfering ribonucleic acid treatment and functional analysis of PGRMC1 mutations. Endocrinology 149 534-543. (doi:10. 1210/en.2007-1050)

Peluso J, Liu X, Gawkowska A \& Johnston-MacAnanny E 2009 Progesterone activates a progesterone receptor membrane component 1-dependent mechanism that promotes human granulosa/luteal cell survival but not progesterone secretion. Journal of Clinical Endocrinology and Metabolism 94 2644-2649. (doi:10.1210/jc.2009-0147)

Peluso JJ, Liu X, Gawkowska A, Lodde V \& Wu CA 2010 Progesterone inhibits apoptosis in part by PGRMC1-regulated gene expression. Molecular and Cellular Endocrinology 320 153-161. (doi:10.1016/ j.mce.2010.02.005)
Peluso JJ, DeCerbo J \& Lodde V 2012a Evidence for a genomic mechanism of action for progesterone receptor membrane component-1. Steroids 77 1007-1012. (doi:10.1016/j.steroids.2012.01.013)

Peluso JJ, Lodde V \& Liu X 2012b Progesterone regulation of progesterone receptor membrane component 1 (PGRMC1) sumoylation and transcriptional activity in spontaneously immortalized granulosa cells. Endocrinology 153 3929-3939. (doi:10.1210/en.2011-2096)

Robker RL, Russell DL, Yoshioka S, Sharma SC, Lydon JP, O'Malley BW, Espey LL \& Richards JS 2000 Ovulation: a multi-gene, multi-step process. Steroids 65 559-570. (doi:10.1016/S0039-128X(00)00114-8)

Rothchild I 1996 The corpus luteum revisited: are the paradoxical effects of RU486 a clue to how progesterone stimulates its own secretion? Biology of Reproduction 55 1-4. (doi:10.1095/biolreprod55.1.1)

Roy SK \& Greenwald GS 1987 In vitro steroidogenesis by primary to antral follicles in the hamster during the periovulatory period: effects of folliclestimulating hormone, luteinizing hormone, and prolactin. Biology of Reproduction 37 39-46. (doi:10.1095/biolreprod37.1.39)

Roy SK \& Greenwald GS 1996 Methods of separation and in-vitro culture of pre-antral follicles from mammalian ovaries. Human Reproduction Update 2 236-245. (doi:10.1093/humupd/2.3.236)

Ruiz de Galarreta CM, Fanjul LF \& Hsueh AJ 1985 Progestin regulation of progesterone biosynthetic enzymes in cultured rat granulosa cells. Steroids 46 987-1002. (doi:10.1016/S0039-128X(85)80006-4)

Rung E, Friberg PA, Shao R, Larsson DG, Nielsen E, Svensson PA, Carlsson B, Carlsson LM \& Billig H 2005 Progesterone-receptor antagonists and statins decrease de novo cholesterol synthesis and increase apoptosis in rat and human periovulatory granulosa cells in vitro. Biology of Reproduction 72 538-545. (doi:10.1095/biolreprod. 104.033878)

Schreiber JR \& Erickson GF 1979 Progesterone receptor in the rat ovary: further characterization and localization in the granulosa cell. Steroids 34 459-469. (doi:10.1016/0039-128X(79)90106-5)

Schreiber JR \& Hsueh JW 1979 Progesterone "receptor" in rat ovary. Endocrinology 105 915-919. (doi:10.1210/endo-105-4-915)

Schreiber JR, Nakamura K \& Erickson GF 1980 Progestins inhibit FSH-stimulated steroidogenesis in cultured rat granulosa cells. Molecular and Cellular Endocrinology 19 165-173. (doi:10.1016/0303-7207(80) 90019-2)

Schreiber JR, Nakamura K \& Erickson GF 1981 Progestins inhibit FSH-stimulated granulosa estrogen production at a post-cAMP site. Molecular and Cellular Endocrinology 21 161-170. (doi:10.1016/03037207(81)90053-8)

Schuster J, Karlsson T, Karlstrom PO, Poromaa IS \& DahI N 2010 Downregulation of progesterone receptor membrane component 1 (PGRMC1) in peripheral nucleated blood cells associated with premature ovarian failure (POF) and polycystic ovary syndrome (PCOS). Reproductive Biology and Endocrinology 8 58. (doi:10.1186/1477-7827-8-58)

Schwarzenbach H, Manna PR, Stocco DM, Chakrabarti G \& Mukhopadhyay AK 2003 Stimulatory effect of progesterone on the expression of steroidogenic acute regulatory protein in MA-10 Leydig cells. Biology of Reproduction 68 1054-1063. (doi:10.1095/biolreprod. 102.009266)

Setty SL \& Mills TM 1987 The effects of progesterone on follicular growth in the rabbit ovary. Biology of Reproduction 36 1247-1252. (doi:10.1095/ biolreprod36.5.1247)

Shao R, Markstrom E, Friberg PA, Johansson M \& Billig H 2003 Expression of progesterone receptor (PR) A and $\mathrm{B}$ isoforms in mouse granulosa cells: stage-dependent PR-mediated regulation of apoptosis and cell proliferation. Biology of Reproduction 68 914-921. (doi:10.1095/biolreprod. 102.009035)

Skiadas CC, Duan S, Correll M, Rubio R, Karaca N, Ginsburg ES, Quackenbush J \& Racowsky C 2012 Ovarian reserve status in young women is associated with altered gene expression in membrane granulosa cells. Molecular Human Reproduction 18 362-371. (doi:10. 1093/molehr/gas008)

Stein LS, Stoica G, Tilley R \& Burghardt RC 1991 Rat ovarian granulosa cell culture: a model system for the study of cell-cell communication during multistep transformation. Cancer Research 51 696-706.

Stouffer RL, Bishop CV, Bogan RL, Xu F \& Hennebold JD 2013 Endocrine and local control of the primate corpus luteum. Reproductive Biology $\mathbf{1 3}$ 259-271. (doi:10.1016/j.repbio.2013.08.002) 
Suchanek M, Radzikowska A \& Thiele C 2005 Photo-leucine and photomethionine allow identification of protein-protein interactions in living cells. Nature Methods 2 261-267. (doi:10.1038/nmeth752)

Suzuki T, Sasano H, Kimura N, Tamura M, Fukaya T, Yajima A \& Nagura H 1994 Immunohistochemical distribution of progesterone, androgen and oestrogen receptors in the human ovary during the menstrual cycle: relationship to expression of steroidogenic enzymes. Human Reproduction 9 1589-1595.

Svensson EC, Markstrom E, Andersson M \& Billig H 2000 Progesterone receptor-mediated inhibition of apoptosis in granulosa cells isolated from rats treated with human chorionic gonadotropin. Biology of Reproduction 63 1457-1464. (doi:10.1095/biolreprod63.5.1457)

Tarlatzis BC, Pazaitou K, Bili H, Bontis J, Papadimas J, Lagos S, Spanos E \& Mantalenakis S 1993 Growth hormone, oestradiol, progesterone and testosterone concentrations in follicular fluid after ovarian stimulation with various regimes for assisted reproduction. Human Reproduction 8 1612-1616.

Thomas P, Pang Y \& Dong J 2014 Enhancement of cell surface expression and receptor functions of membrane progestin receptor $\alpha$ by progesterone receptor membrane component 1 (PGRMC1): evidence for a role of PGRMC1 as an adaptor protein for steriod receptors. Endocrinology 155 1107-1119. (doi:10.1210/en.2013-1991)

Wendler A \& Wehling M 2013 PGRMC2, a yet uncharacterized protein with potential as tumor suppressor, migration inhibitor, and regulator of cytochrome P450 enzyme activity. Steroids 78 555-558. (doi:10.1016/ j.steroids.2012.12.002)
Yang T, Espenshade PJ, Wright ME, Yabe D, Gong Y, Aebersold R, Goldstein JL \& Brown MS 2002 Crucial step in cholesterol homeostasis: sterols promote binding of SCAP to INSIG-1, a membrane protein that facilitates retention of SREBPs in ER. Cell 110 489-500. (doi:10.1016/ S0092-8674(02)00872-3)

diZerega GS \& Hodgen GD 1982 The interovarian progesterone gradient: a spatial and temporal regulator of folliculogenesis in the primate ovarian cycle. Journal of Clinical Endocrinology and Metabolism 54 495-499. (doi:10.1210/jcem-54-3-495)

Zhu Y, Bond J \& Thomas P 2003a Identification, classification, and partial characterization of genes in humans and other vertebrates homologous to a fish membrane progestin receptor. PNAS 100 2237-2242. (doi:10.1073/pnas.0436133100)

Zhu Y, Rice CD, Pang Y, Pace M \& Thomas P 2003 b Cloning, expression, and characterization of a membrane progestin receptor and evidence it is an intermediary in meiotic maturation of fish oocytes. PNAS $\mathbf{1 0 0}$ 2231-2236. (doi:10.1073/pnas.0336132100)

Received 13 November 2013

First decision 21 January 2014

Revised manuscript received 6 February 2014

Accepted 10 February 2014 